\title{
Ten year follow up of patients with single vessel coronary artery disease that was suitable for percutaneous transluminal coronary angioplasty
}

\author{
NICOLAS DANCHIN, ARIANE BRENGARD, GÉRARD ETHEVENOT, \\ SERGE BRIANÇON, MICHEL CUILLIËRE, ETIENNE ALIOT, \\ CLAUDE PERNOT, JEAN-M GILGENKRANTZ, PIERRE MATHIEU, \\ FRANÇOIS CHERRIER \\ From the Department of Cardiology and Cardiovascular Surgery, University Hospital of Nancy-Brabois, \\ Vandoeuvre-lès-Nancy, France
}

SUMMARY The 10 year outcome of patients with single vessel coronary artery disease who underwent coronary angiography more than 10 years before and who would have been potential candidates for percutaneous transluminal coronary angioplasty had it been available then is reported. Long term follow up data were obtained in 96 (91 men, five women; mean age 48 years) of 105 consecutive patients with single vessel coronary artery disease $(>70 \%$ stenosis), judged suitable for coronary angioplasty. Fifty patients had coronary bypass surgery within six months of catheterisation (surgical group) and 46 were treated medically (medical group). At entry to the study more patients in the surgical group had unstable angina, but fewer had a previous history of myocardial infarction. Ten year survival was $91 \%$ and remained excellent in all the subsets analysed. Moreover, the quality of life of these patients was good. Over the 10 year follow up, 16 $(36 \%)$ of the patients treated medically and $13(26 \%)$ in the surgical group were admitted to hospital because of cardiovascular events (including late coronary surgery in four of the patients treated medically). Lastly, 54/69 (78\%) of the patients who were employed before catheterisation resumed work and $29(42 \%)$ were still employed 10 years later.

Although these data must be interpreted with care because of the limitations inherent in all retrospective studies, it appears that the long term results of conventional medical or surgical treatment are excellent in patients with single vessel coronary artery disease in whom percutaneous transluminal coronary angioplasty is now an option.

Percutaneous transluminal coronary angioplasty is now widely used to treat coronary artery diseasemore than 70000 procedures were performed in the United States in $1984 .^{1}$ Though the indications of the procedure have been extended considerably over the past five years, most patients undergoing percutaneous transluminal coronary angioplasty still have single vessel disease. To date, however, there is no clear cut evidence that percutaneous transluminal coronary angioplasty is better than medical treatment or coronary artery surgery in such patients. Because

Requests for reprints to Dr Nicolas Danchin, Department of Cardiology and Cardiovascular Surgery, CHU Nancy-Brabois, 54500-Vandoeuvre-lès-Nancy, France.

Accepted for publication 30 September 1987 there is no continuing prospective randomised study of percutaneous transluminal coronary angioplasty compared with coronary artery bypass surgery or medical treatment in patients with single vessel disease, retrospective studies must be used to provide standards for the evaluation of the results of the new treatment. We have studied the long term outcome of patients with single vessel disease who underwent coronary arteriography ten years before and who would have been suitable candidates for percutaneous transluminal coronary angioplasty had the technique been available then.

\section{Patients and methods}

INCLUSION CRITERIA

The study population was chosen from the coronary 
angiographic registry of our centre. The coronary angiograms of a consecutive series of 141 patients admitted to our department from April 1972 to March 1976 who had a subtotal stenosis of the luminal diameter $(>70 \%)$ of one of the three main coronary arteries, without involvement of the other coronary arteries ( $<50 \%$ stenosis), were reviewed by two independent observers who were experienced in coronary angioplasty. Only those patients who had a stenosis that was judged to be suitable for percutaneous transluminal coronary angioplasty were included-that is a single stenosis, concentric or eccentric, not calcified, no longer than $1.5 \mathrm{~cm}$, not significantly affecting a side branch and sited in segments 1, 2, 3 (right coronary artery), 12, 13 (left anterior descending), or 18, 19, 20 (left circumflex) of the coronary arteries as defined by the Coronary Artery Surgery Study. ${ }^{2}$

\section{FOLLOW UP}

The long term outcome of the patients was studied by a simple questionnaire sent to all patients who were presumed to be alive. Furthermore, information was obtained from the patients' physicians and cardiologists. When no information was obtained by these different methods, we contacted the registries in the patients' birthplaces to check whether their death had been registered; however, a patient was believed to be alive only if direct information was obtained from the patient, his family, or his physicians. Patients lost to follow up during the follow up period were included in the study up to the time they were last known to be alive.

\section{DATA ANALYSIS}

Survival rates from the time of coronary angiography were calculated by life table methods. Baseline variables in the medical and surgical groups were compared by $\chi^{2}$ tests (Yates' correction when appropriate) for discrete variables and Student's $t$ tests for continuous variables.

\section{Results}

\section{POPULATION}

Of the 2265 patients catheterised during the study period, $141(6.2 \%)$ had a subtotal $(>70 \%)$ stenosis in a single coronary artery. Of these, 36 were excluded upon review of the coronary angiogram for the reasons listed in table 1 . The table gives only the main exclusion criterion for each patient.

One hundred and five consecutive patients had a single vessel stenosis that was judged to be suitable for percutaneous transluminal coronary angioplasty. Nine $(8.6 \%)$ of these, four of whom were foreigners, were lost to follow up. The study population
Table 1 Reasons why patients were excluded when the coronary angiogram was reviewed

\begin{tabular}{ll}
\hline Angiographic characteristic & Patients (No) \\
\hline Near obstruction & 10 \\
Distal narrowing & 6 \\
Additional distal narrowing & 5 \\
Narrowing at bifurcation & 5 \\
Calcified deposits & 4 \\
Length of narrowing & 3 \\
Superimposed coronary artery spasm & 3 \\
\hline
\end{tabular}

therefore comprised 96 patients (91 men and five women; mean (SD) age 47.9 (7.9) years). Fifty patients had coronary artery surgery (internal mammary artery graft 35, saphenous vein graft 15) within six months of catheterisation. Forty six patients were treated medically, four of them underwent late coronary artery surgery $6-9$ years after catheterisation.

Table 2 gives the main baseline clinical and angiographic characteristics of the two groups. In the surgical group more patients presented with unstable angina pectoris $(25(50 \%)$ vs $9(20 \%), \mathrm{p}<0.01)$, whereas in the medical group more patients were symptom free or had atypical chest pain $(15(33 \%)$ vs $3(6 \%), p<0.01)$. Similarly, more medically treated patients had had a previous episode of myocardial infarction $(21(46 \%)$ vs $9(18 \%), p<0.01)$. Left ventricular ejection fraction could not be measured in five medically treated and seven surgically treated patients (no left ventricular angiogram in one and four patients respectively, and left ventricular angiogram unsuitable for determination of ejection fraction in four and three patients respectively); three $(7 \%)$ patients in the surgical group and eight $(20 \%)$ in the medical group had an ejection fraction below 0.50 (NS). The left anterior descending artery was most commonly affected in both treatment groups.

\section{TEN YEAR SURVIVAL}

For the whole study population ten year actuaria survival was $91 \%$. In four of the nine patients who died during follow up the cause of death was directly related to ischaemic heart disease; two patients died of cancer and the cause of death was unknown in three patients. Furthermore, ten year survival was excellent in all of the subsets studied. Ten year survival was $91 \%$ for the medical group and $90 \%$ for the surgical group (fig 1). When analysed according to the vessel affected (fig 2 ) survival was $91 \%$ for left anterior descending stenoses (medical group 93\%, surgical group $\mathbf{9 0} \%$ ), $\mathbf{8 9} \%$ for right coronary artery stenoses $(90 \%$ in both treatment groups), and $92 \%$ in patients with stenoses of the left circumflex (medical group $90 \%$, surgical group $100 \%$ ). In patients with 
Ten year outcome in single vessel disease that was suitable for coronary angioplasty

Table 2 Baseline characteristics in patients treated medically or surgically

\begin{tabular}{|c|c|c|c|}
\hline Variable & Medical treatment $(n=46)$ & Surgical treatment $(n=50)$ & pvalue \\
\hline \multicolumn{4}{|l|}{ Sex: } \\
\hline $\begin{array}{l}\text { Male } \\
\text { Female }\end{array}$ & & $\begin{array}{r}47 \\
3\end{array}$ & NS \\
\hline Mean age (SD) (year) & $47 \quad(7)$ & $49 \quad(9)$ & NS \\
\hline $\begin{array}{l}\text { Mean duration of symptoms before coronary } \\
\text { angiography (SD) (mnth) }\end{array}$ & $10 \cdot 5(11)$ & $11 \cdot 5(21)$ & NS \\
\hline \multicolumn{4}{|l|}{ Reason for coronary angiography: } \\
\hline Unstable angina & 9 & 25 & \\
\hline Stable angina & 22 & 22 & 0.01 \\
\hline Atypical chest pain/abnormal rest ECG & 15 & 3 & \\
\hline Previous myocardial infarction & $21(46 \%)$ & $9(18 \%)$ & 0.01 \\
\hline Left anterior descending & 27 & 38 & \\
\hline $\begin{array}{l}\text { Right coronary artery } \\
\text { Left circumflex }\end{array}$ & $\begin{array}{r}9 \\
10\end{array}$ & $\begin{array}{l}9 \\
3\end{array}$ & NS \\
\hline Ejection fraction $<0.50$ & $8 / 41(20 \%)$ & $3 / 43(7 \%)$ & NS \\
\hline
\end{tabular}

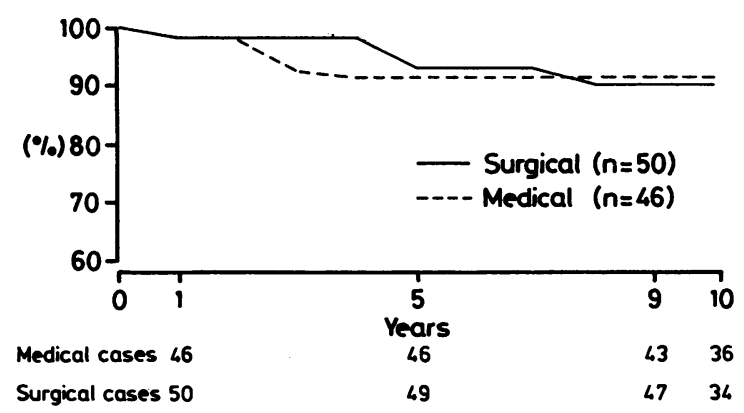

Fig 1 Ten year actuarial survival of potential candidates for percutaneous transluminal coronary angioplasty according to treatment. $M$, medical group; $S$, surgical group.

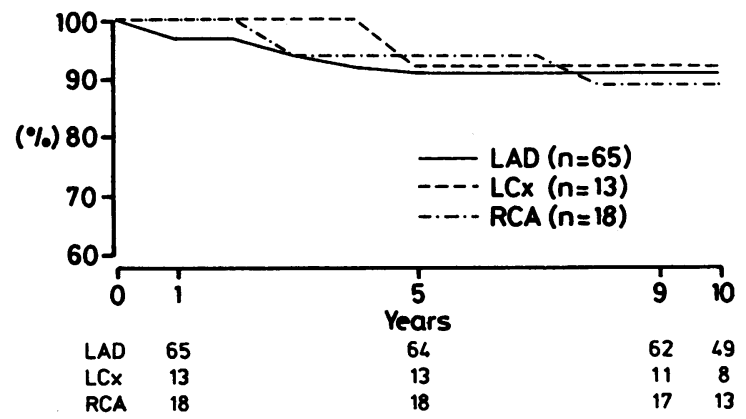

Fig 2 Ten year actuarial survival of potential candidates for percutaneous transluminal coronary angioplasty according to affected coronary artery. $L A D$, left anterior descending; LCx, left circumflex; $R C A$, right coronary artery.

angina at the time of catheterisation, ten year survival was $90 \%$ (89\% for surgically treated patients and $90 \%$ for medically treated patients); when analysed according to the vessel involved, all subsets of patients had an $86 \%$ or higher survival at ten years.

Lastly, ten year survival in patients with previous myocardial infarction was $93 \%-100 \%$ in the surgical group ( $n=9$ ) and $90 \%$ in the medical group ( $n$ $=21$ ).
Table 3 Quality of life at follow up

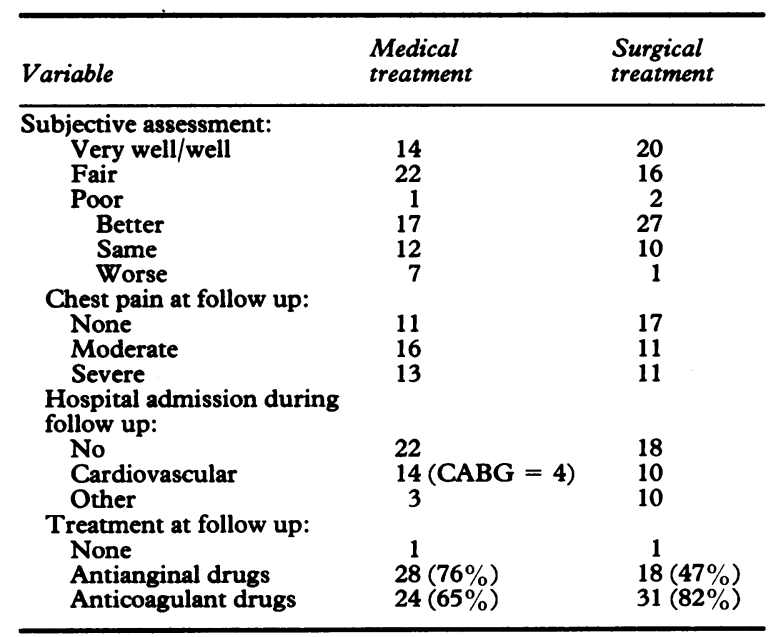

Some of the patients answered only part of the questionnaire.

\section{QUALITY OF LIFE}

The quality of life was assessed in the patients who answered all or part of the questionnaire ( 40 patients in the medical group and 39 patients in the surgical group (table 3).

At follow up most patients felt well: $14 / 37$ (38\%) of the medically treated and $20 / 38(53 \%)$ of the surgically treated patients felt well or very well. Twenty seven $(71 \%)$ of the surgically treated patients and 19 $(47 \%)$ of the medically treated patients reported an improvement after catheterisation. Angina pectoris is always difficult to assess by means of a questionnaire; however, $11(28 \%)$ of the patients in the medical group and $18(46 \%)$ in the surgical group did not complain of chest discomfort.

During the 10 year follow up period, $14(36 \%)$ patients in the medical group and $10(26 \%)$ patients in the surgical group were admitted to hospital because of cardiovascular events. In the medical 
Table 4 State of employment of patients treated medically or surgically

\begin{tabular}{|c|c|c|}
\hline & Medical group & Surgical group \\
\hline $\begin{array}{l}\text { Employed before coronary } \\
\text { angiography }\end{array}$ & 36 & 33 \\
\hline $\begin{array}{l}\text { Return to work after coronary } \\
\text { angiography or surgery }\end{array}$ & $30(83 \%)$ & $24(73 \%)$ \\
\hline Still working at follow up & $19(53 \%)$ & $10(30 \%)$ \\
\hline
\end{tabular}

group four $(10 \%)$ patients underwent late coronary artery bypass surgery 6-9 years after the initial catheterisation; three $(8 \%)$ additional patients were admitted to hospital for myocardial infarction; the other reasons for hospital admission were angina, cerebrovascular accident, syncope, and severe haematoma in a patient treated with oral anticoagulants. In the surgical group three patients were admitted because of recurrent angina, and miscellaneous reasons were found in the remaining patients (pacemaker implantation, near-syncope, congestive heart failure, cerebrovascular accident, arteriography of the leg).

At follow up only one patient in each treatment group was not on medical treatment. The drug regimens were varied; however, $28(76 \%)$ patients in the medical group and $18(47 \%)$ in the surgical group were on antianginal treatment, while $24(65 \%)$ and $31(82 \%)$ respectively were still taking oral anticoagulants.

EMPLOYMENT

Of the 69 patients who were employed before catheterisation, $54(78 \%)$ had resumed work and 29 $(42 \%)$ were still employed at the time of follow up. In the medical group $83 \%$ of the patients returned to work after catheterisation and $53 \%$ were still working at follow up. In the surgical group $73 \%$ of the patients resumed work after operation and $30 \%$ were still working at the time of the survey.

\section{Discussion}

The present study shows that excellent long term results were obtained with conventional medical or surgical treatment in patients with single vessel coronary artery stenoses that were technically suitable for percutaneous transluminal coronary angioplasty. This retrospective study was not designed to compare the results of medical and surgical treatment and the populations in both treatment groups clearly have distinct baseline characteristics. It has the potential limitations of all retrospective studies. The patients were catheterised 10-15 years ago and coronary heart disease mortality has declined since then; also medical treatment has changed and new classes of medications, such as calcium antagonists are now available.

Ten year survival is very high $(91 \%)$ and the analysis shows that it remains excellent in all subsets. ․ㅡ․ Such survival rates resemble those reported in $\frac{\bar{c}}{\sigma}$ populations with normal coronary arteriograms. ${ }^{3-50} \Omega$ These results accord with the currently available datan of the Coronary Artery Surgery Study randomised? trial for patients with single vessel disease (five year ${ }_{-}^{\circ}$ survival $96 \%$ in the surgical group and $93 \%$ in the $\vec{\omega}$ medical group). ${ }^{6}$ In the Veterans Administrations randomised trial of coronary bypass surgery for stable angina the eleven year survival rate in patientsor with one vessel disease was $70 \%$ for the surgicaliw group and $65 \%$ for the medical group. ${ }^{7}$ The higheriv survival rate found in the present series might be explained in part by the use of internal mammarys artery grafts in most of our surgically treatedpatients, whereas patients in the Veterans Adminis- $\frac{3}{0}$ tration trial had saphenous vein grafts in which longọ term patency is much lower. ${ }^{8}$ The difference in survival of the medically treated groups is difficult to ${ }_{\infty}$ explain: all patients in the Veterans Administration. ${ }^{\circ}$ trial but only two thirds in our medical group had angina pectoris at entry to the study; the drug regimen of the patients during follow up was alsoprobably different and most of our patients had received oral anticoagulants, which may be impor- $-\Phi$ tant because coronary artery thrombosis is the main $\overrightarrow{\vec{F}}$ cause of myocardial infarction. ${ }^{9}$ Moreover, there is $\exists$ no means of knowing how many of the patients with one vessel disease in the Veterans Administration? study or in the Coronary Artery Surgery Study randomised trial had coronary stenoses that were technically suitable for percutaneous transluminal coronary angioplasty.

To our knowledge, only two studies have analysed the outcome in potential cadidates for percutaneous transluminal coronary angioplasty..$^{11}$ Both, however, have a shorter follow up (four and five years respectively). In the series from Duke University $\rightarrow$ five year survival is $97 \%$ in the medical group and $91 \%$ in patients who were treated surgically. ${ }^{11}$ In the $N$ series of the Coronary Artery Surgery Study, $N$ however, the coronary angiograms were not reviewedN and factors such as the assessibility of the lesion to the $e_{\sigma}^{\omega}$ balloon catheter or the presence of calcification were not assessed.

Beside these favourable results in terms of survival, the quality of life of the patients over the ten year follow up period is satisfactory. Although nearlyo all patients were on medical treatment at follow up, $\mathbb{D}$ most felt well and few felt worse than at the time of catheterisation. Four $(10 \%)$ of the medically treated patients had late coronary bypass surgery and an 
additional $10(26 \%)$ required admission to hospital because of cardiovascular events; there was a similar proportion $(10(26 \%))$ of late hospital admissions for cardiovascular events in the surgical group. These results accord with reported studies of potential percutaneous transluminal coronary angioplasty candidates. ${ }^{1011}$

Lastly, employment data are also satisfactory, with $54(78 \%)$ of the patients who were employed resuming work after catheterisation or surgery. Similar reemployment rates were found in a recent study of employment after percutaneous transluminal coronary angioplasty in France, ${ }^{12}$ and in a report from the National Heart, Lung, and Blood Institute coronary angioplasty registry. ${ }^{13}$

Patients with single vessel disease that could be treated with percutaneous transluminal coronary angioplasty have an excellent long term outcome with standard medical or surgical treatment and it seems doubtful that percutaneous transluminal coronary angioplasty can improve the prognosis of such patients. Percutaneous transluminal coronary angioplasty, however, is likely to improve symptoms as much as surgical treatment and at a lower cost. ${ }^{14}$ Similarly, drug requirements should be less after percutaneous transluminal coronary angioplasty than with conventional medical treatment for angina. As a prospective randomised trial of percutaneous transluminal coronary angioplasty and conventional treatment in patients with single vessel disease is now unlikely, retrospective studies, although they are of a more limited scientific value, are the only way in which to compare the long term results of percutaneous transluminal coronary angioplasty. The present study is continuing and should provide information for the evaluation of the current results of percutaneous transluminal coronary angioplasty.

\section{References}

1 Kent KM. Indications for transluminal coronary angioplasty. Circulation 1985;72(suppl V):V-166-8.

2 Principal investigators of CASS and their associates. National Heart, Lung, and Blood Institute Coronary Artery Surgery Study. Circulation 1981; 63(suppl I):I-1-39.

3 Bruschke AVC, Proudfit WL, Sones FM Jr. Clinical course of patients with normal and slightly or moderately abnormal coronary arteriograms. A follow-up study on 500 patients. Circulation 1973;47:936-45.

4 Humphries JO, Kuller L, Ross RS, Friesinger GC, Page EE. Natural history of ischemic heart disease in relation to arteriographic findings. A twelve year study of 224 patients. Circulation 1974;49:489-97.

5 Kemp HG, Kronmal RA, Vlietstra RE, Frye RL, and participants in the Coronary Artery Surgery Study. Seven year survival of patients with normal or near normal coronary arteriograms: a CASS registry study. J Am Coll Cardiol 1986;7:479-83.

6 CASS principal investigators and their associates. Myocardial infarction and mortality in the Coronary Artery Surgery Study (CASS) randomized trial. $N$ Engl J Med 1984;310:750-8.

7 The Veterans Administration Coronary Artery Bypass Surgery Cooperative Study Group. Eleven year survival in the Veterans Administration randomized trial of coronary bypass surgery for stable angina. $N$ Engl J Med 1984;311:1333-9.

8 Grondin CM, Campreau L, Lespérance J, Enjalbert M, Bourassa MG. Comparison of late changes in internal mammary artery and saphenous vein grafts in two consecutive series of patients 10 years after operation. Circulation 1984;70(suppl I):I-208-12.

9 De Wood MA, Spores J, Notske R. Prevalence of total coronary occlusion during the early hours of transmural myocardial infarction. $N$ Engl J Med 1980; 303:897-902.

10 Holmes DR Jr, Vlietstra RE, Fisher LD, et al. Followup of patients from the Coronary Artery Surgery Study (CASS) potentially suitable for percutaneous transluminal coronary angioplasty. Am Heart J 1983;106:981-8.

11 Hlatky MA, Califf RM, Kong Y, Harrell FE Jr, Rosati RA. Natural history of patients with single-vessel disease suitable for percutaneous transluminal coronary angioplasty. Am J Cardiol 1983;52:225-9.

12 Danchin N, Cuillière M, Mathieu P, Cherrier F, Faivre G. Réinsertion socio-professionelle après angioplastie transluminale coronaire. Arch Mal Coeur 1984; 77:993-7.

13 Holmes DR Jr, Van Raden MJ, Reeder GS, et al. Return to work after coronary angioplasty: a report from the National Heart, Lung, and Blood Institute percutaneous transluminal coronary angioplasty registry. Am J Cardiol 1984;54:48C-51C.

14 Reeder GS, Krishan I, Nobrega FT, et al. Is percutaneous transluminal coronary angioplasty less expensive than bypass surgery? $N$ Engl $J$ Med 1984;311: 1157-62. 